\title{
拡散反射と正反射成分とを有する室内の相互反射の 一近似値計算法について
}

\author{
専門会員 磯 村稔* \\ An Approximate Calculation of Interreflections in Rooms with Mixed \\ Diffuse-Specular Surfaces \\ Minoru Isomura (Fellow Member) \\ (Department of Electrical Engineering, College of Industrical Technology Nihon University)
}

\begin{abstract}
The Calculation of luminous transfer in spaces bounded by surfaces that exhibit specular aud/or diffuse reflections were extensively studied by O'Brien and associates in the middle of 1960's.

In the conventional calculation, the number of terms of the $\phi$-function and consequently computation time increase as the number of surface elements increses.

This paper describes an approximate calculation of interreflections in rooms with both diffuse and specular surfaces. The approximation is based on the assumption that surfaces with both diffuse and specular reflections can be treated solely as uniform diffusers for any interreflection.

For evaluation, luminous exitance is calculated for luminous panels of different sizes in a room of any shape.

The results showed that approximation errors were less than one percent.
\end{abstract}

\section{1. まえがき}

室内照明計算法については，すでに数多くの論文が発表され， 相互反射後の各面光束発散度比が求められている.なかでも，抎 散反射と正反射成分とを同時に有する反射面からなる室内照明計 算法は，1960 年代に O'Brien らによって発表され，各面間の光 束伝達関数をいろいろな室指数, 拡散反射成分に対する正反射成 分の割合に対して計算を行ない122)，飯塚らは天井の一部にパネ ル光源があり, 室内の一つの壁面が払散反射と正反射成分とを有 するときの照度計算法について報告している32。

また著者も縮尺モデル室を用い，その一つの壁面が正反射成分 だけを有する矩形室の作業面に入射する全光束量に，その壁面が 及よぼす影響について報告してきだ)5.

近年，より実際的な照明設計を行ならため，その計算法におい て室を構成する面素数を多く取り入れる傾向にある ${ }^{6}$.

このため従来の計算法では，面素数の増加に伴い $\phi$-関数の計 算数が増加し，非常に煩雑となることが考えられる.

本論文は，各面間の相互反射に抋いて払散反射と正反射成分と を有する壁面を，仮りに完全払散反射面として取り扱い，一壁面 が払散反射と正反射成分とを有する室内の相互反射について，一 つの近似計算法を試み, その計算結果と従来の計算法による結果

* 日本大学生産工学部電気工学科

本論文の一部は，昭和 57 年照明学会全国大会で諢演したものである
とを, 完全执散性面光源の大きさや形状について比較したもの で, 相互反射に及ぼす正反射成分の影響のうち 1 回反射による影 響だけを考虑することにより, 従来の計算法における手間のかか る $\phi$-関数の計算を行なわずに, 比較的簡単に $1 \%$ 以内の誤差で 近似計算が可能であることを示した.

\section{2. 近似計算法}

図 1 は計算に用いた矩形室で, 長さ $L$, 幅 $W$, 高さ $H_{m}$ であ る。

室は完全拡散性面光源 $S_{1}$, 光源を除いた天井面 $S_{2}$, 四つの壁 面 $S_{3}, S_{4}, S_{5}, S_{6}$ そして床面（作業面） $S_{7}$ により構成されて いる.

この 7 面素のらち, 面素 5 の壁面 $S_{5}$ が払散反射と正反射成分 とを有する面とし，この面の全反射率 $\rho_{5}$ は正反射率 $\rho_{85}$ と拡散 反射率 $\rho_{D 5}$ との和 $\left(\rho_{5}=\rho_{D 5}+\rho_{85}\right)$ で表わされ7), 入射角によっ てその反射率が変化しないものとしてここでは取り扱う.

また，この壁面 $S_{5}$ の正反射成分による各面の虚像を図 1 に破 線で示し，たと学ば面光源 $S_{1}$ の壁面 $S_{5}$ による虚像は $S_{1(5)}$ とし て示してある.なおその他の面は完全払散性反射面とし, その全 反射率は払散反射率に等しく,

$\rho_{1}=\rho_{D 1}, \quad \rho_{2}=\rho_{D 2}, \quad \rho_{3}=\rho_{D 3}, \quad \rho_{4}=\rho_{D 4}, \quad \rho_{6}=\rho_{D 6}, \quad \rho_{7}=\rho_{D 7}$ である.

完全拡散性面光源 $S_{1}$ の 初期光束発散度を $M_{01}$ とする と, 壁 


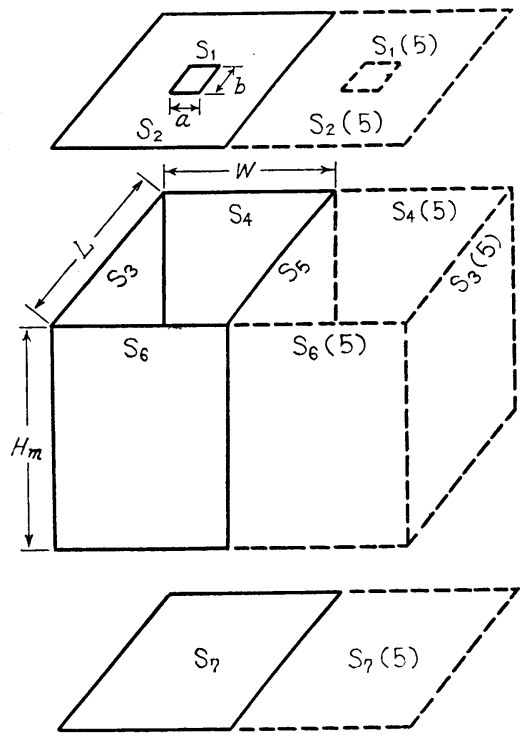

図 1 矩形室と壁面 $S_{5}$ の正反射成分に よる各面の虚像（破線）

面 $S_{5}$ から 1 回反射し，面 $S_{i}$ に入射する間接光束量 $F_{1 m i}$ は，

$$
F_{1 m i}=A_{1}\left\{\rho_{s 5} F_{1(5)-i}+\rho_{D 5} F_{1-5} F_{5-i}\right\} M_{01}
$$
となる・

ここで, $A_{1}$ : 完全払散性面光源 $S_{1}$ の面積 $(a \times b)$

$F_{i-j}$ : 面 $S_{i}$ より面 $S_{j}$ への固有入射光束係数

$F_{1(5)-i}$ : 壁面 $S_{5}$ の正反射成分によって生じた面光源の虚 像 $S_{1(5)}$ より面 $S_{i}$ への固有入射束係数

いま，この桩散反射と正反射成分とを有する壁面 $S_{5}$ を仮りに 完全拡散性壁面として考元, この正反射成分 $\left(\rho_{s 5}\right)$ を払散反射成 分 $\left(\rho_{D 5}{ }^{\prime}\right)$ として取り扱う $\left(\rho_{5}=\rho_{D_{5}}+\rho_{D^{\prime}}{ }_{5}, \rho_{D^{\prime}}{ }_{5}=\rho_{s 5}\right)$.

この完全払散性壁面 $S_{5}$ から 1 回反射し，面 $S_{i}$ へ入射する間 接光束量 $F_{1 d i}$ は,

$F_{1 d i}=A_{1} \rho_{5}\left\{\begin{array}{llll}F_{1-5} & F_{5-i}\end{array}\right\} M_{01}$ (2)

この両式より, 壁面 $S_{5}$ の反射配光の相違による面 $S_{i}$ 一入射 する間接光束量の差 $\Delta F_{1 i}$ は,

$$
\begin{aligned}
& \Delta F_{1 i}=F_{1 m i}-F_{1 d i} \\
& =A_{1}\left\{\rho_{85} F_{1(5)-i}-\left(\rho_{5}-\rho_{D 5}\right) F_{1-5} F_{5-1}\right\} M_{01} \cdots(3) \\
& =A_{1} \rho_{s 5}\left\{F_{1(5)-i}-F_{1-5} F_{5-i}\right\} M_{01}
\end{aligned}
$$

また上式より，1回反射による面 $S_{i}$ の 光束発散度 の 差 $\Delta M_{1 i}$ は,

$$
\Delta M_{1 i}=\frac{\rho_{i} A_{1}}{A_{i}} \rho_{s 5}\left\{F_{1(5)-i}-F_{1-5} F_{5-i}\right\} M_{01}
$$

となる.

ここで，いま壁面に払散反射と正反射成分とを有する室と反射 面がすべて完全拡散性である室との各面にお沙る光束発散度の差 が，この壁面から 1 回反射による各面への光束発散度の差 $\Delta M_{1 i}$ に等しいと仮定すると年,

$$
M_{i m}=M_{i d}+\Delta M_{1 i}
$$

ここで， $M_{i m}$ ：壁面に扗散反射と正反射成分とを有する室に㧤 ける面 $S_{i}$ の相互反射後の光束発散度

$M_{i, d}$ ：反射面がすべて完全扗散性である室に括ける面 $S_{i}$ の相互反射後の光束発散度

したがって, 面 $S_{i}$ の相互反射後の光束発散度 $M_{i(a)}$ は

$$
M_{i(a)}=M_{0 i}+\Delta M_{1 i}+\rho_{i}\left\{F_{i-1} M_{1(a)}+F_{i-2} M_{2(a)}\right.
$$

$$
\left.+\cdots \cdots+F_{i-7} M_{7(a)}\right\}
$$

となる.なおここで添字の $(a)$ は近似計算法であることを示す.

この近似計算法に拀いて，拡散反射と正反射成分とを有する壁 面を完全払散壁面として取り扱っているので，拡散反射と正反射 成分とを有する壁面の光束発散度 $M_{5}{ }^{\prime} a$ は, 次式によって求めら れる.

$$
M_{5}^{\prime}{ }_{a}=\frac{\rho_{D 5}}{\rho_{5}} M_{5(a}
$$

下式(8)は，従来より用いられている計算式である ${ }^{133)}$.

$$
M_{i}=M_{0 i}+\rho_{d i}\left\{\phi(i, 1) M_{1}+\phi(i, 2) M_{2}\right.
$$$$
\left.+\cdots \cdots+\phi(i, 7) M_{7}\right\}
$$

ここで, $\phi(i, j): \phi$ 関数, 面 $S_{i}$ より面 $S_{j}$ への固有入射光束 係数と, 正反射面により生じた面 $S_{i}$ の虚像 より面 $S_{j}$ への固有入射光束係数と正反射率 との積との和

$\phi(i, j)=F_{i-j}+\rho_{s n} F_{i(n)-j}$

\section{3. 間接光束量の差 $\Delta F_{1 i}$}

図 1 の長さ，幅ともに $5 \mathrm{~m}$ の休面からなる矩形室を考兄，その 天井面の一部に単位初期光束発散度をもつ完全払散性正方形光源 があるとき，壁面 $S_{5}$ より 1 回反射し，各面へ入射する間接光束 量を, 壁面 $S_{5}$ が正反射成分だけの場合 $\left(\rho_{5}=\rho_{s 5}\right)$ と, 完全扗散 性の場合 $\left(\rho_{5}=\rho_{D 5}\right)$ とについて求め, これより両者の差である 各面の間接光束量の差 $\Delta F_{1 i}$ を求めた.

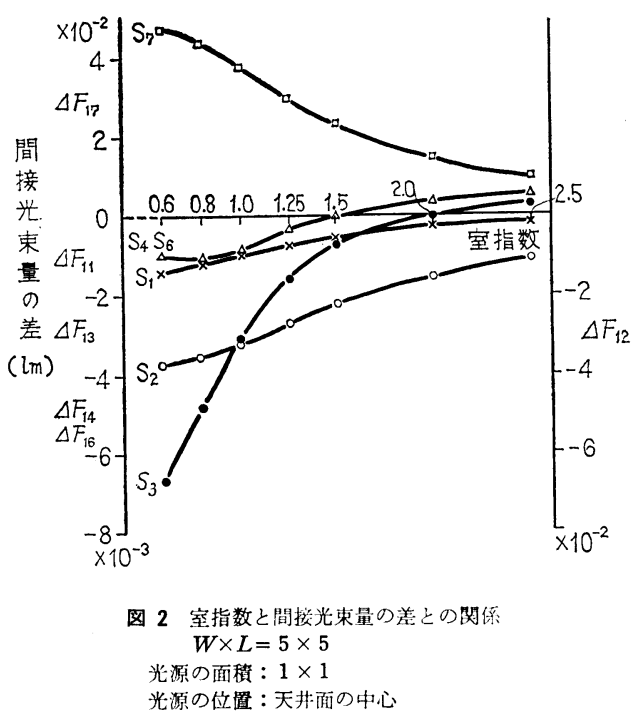

図 2 は, 一辺が $1 \mathrm{~m}$ の完全拡散性正方形光源を天井面の中心 に取り付けた場合の空指数と間接光束量の差との関係を, 全反射 率 $\rho_{5}$ を 1.0 として求めたものである. なお, 図の縦軸は面素 $S_{i}$ の間接光束量の差を $\Delta F_{1 i}$ として示してある.

困中で間接光束量の差が正の場合は, 正反射成分だけの壁面よ り 1 回反射し，入射する間接光束量が完全㧪散性壁面より大であ ることを示している.

また，壁面 $S_{5}$ が正区射成分だけの場合は，その区射指向特性 により壁面から 1 回反射し, 光源面 $S_{1}$ と光源を除いた天井面 $S_{2}$ に入射する間接光束量はゼロである.

間接光束量の差は, 光源を除いた天井面 $S_{2}$ で負に, 作業面 $S_{7}$ で正に大きくなって扣り，壁面の反射配光の相違による影響が他 
の面に比して大きく現われることを示している.これは, 光源を 除いた天井面 $S_{2}$ では，前述したように正反射成分だけの壁面か ら 1 回反射し，入射する間接光束量はゼロであるからで，作業面 $S_{7}$ では正反射成分だけの壁面の反射指向特性により，作業面に 入射する間接光束量が完全拡散性壁面の場合に比して, 著しく大 きくなるものと考觉られる。

\section{4. 近似計算法による各面の光束発散度比}

前述の近似計算法により各面の光束発散度比を求め，(8)式によ って求めた各面の光束発散度比を真值と考兄, それらの結果を比 較した.この計算は光源の初期光束発散度を $M_{01}$ としてある.

麦 1 各面の光束発散度比

$W \times L=5 \times 5$, 光源の面䅡 $1 \times 1$

光源位椹 : 天井面の中心

$\rho_{d 1}=0.9, \rho_{d 2}=0.7, \rho_{d 3}=o_{d 4}=\rho_{s 5}=\rho_{d 6}=\rho_{5}, \rho_{d 7}=0.3$

\begin{tabular}{|c|c|c|c|c|c|}
\hline \multirow{2}{*}{ 室指数 } & 反射率 & \multicolumn{2}{|c|}{$\rho_{5}=0.7$} & \multicolumn{2}{|c|}{$\rho_{5}=0.5$} \\
\hline & $M_{i} / M_{01}$ & 真 & 近似值 & 真 & 近 似 傎 \\
\hline \multirow{6}{*}{0.6} & $M_{1} / M_{01}$ & 1.010 & 1.010 & 1.006 & 1.006 \\
\hline & $M_{2} / M_{01}$ & $7.537 \times 10^{-3}$ & $7.556 \times 10^{-3}$ & $4.343 \times 10^{-3}$ & $4.325 \times 10^{-3}$ \\
\hline & $M_{2} / M_{01}$ & $1.323 \times 10^{-2}$ & $1.321 \times 10^{-2}$ & $7.248 \times 10^{-3}$ & $7.250 \times 10^{-3}$ \\
\hline & $M_{4} / M_{01}$ & $1.330 \times 10^{-2}$ & $1.331 \times 10^{-2}$ & $7.303 \times 10^{-3}$ & $7.303 \times 10^{-3}$ \\
\hline & $M_{6} / M_{01}$ & $1.330 \times 10^{-2}$ & $1.331 \times 10^{-2}$ & $7.303 \times 10^{-3}$ & $7.303 \times 10^{-3}$ \\
\hline & $M_{7} / \bar{M}_{01}$ & $7.654 \times 10^{-3}$ & $7.664 \times 10^{-3}$ & $5.945 \times 10^{-3}$ & $5.957 \times 10^{-3}$ \\
\hline \multirow{6}{*}{1.25} & $M_{1} / M_{01}$ & 1.011 & 1.010 & 1.008 & 1.008 \\
\hline & $M_{2} / M_{01}$ & $8.484 \times 10^{-3}$ & 8. $426 \times 10^{-3}$ & $6.188 \times 10^{-3}$ & $6.128 \times 10^{-3}$ \\
\hline & $M_{3} / M_{01}$ & $1.409 \times 10^{-2}$ & $1.403 \times 10^{-2}$ & $8.462 \times 10^{-3}$ & $8.452 \times 10^{-3}$ \\
\hline & $M_{4} / M_{01}$ & $1.412 \times 10^{-2}$ & $1.409 \times 10^{-2}$ & $8.492 \times 10^{-3}$ & $8.484 \times 10^{-3}$ \\
\hline & $M_{6} / M_{01}$ & 1. $412 \times 10^{-2}$ & $1.409 \times 10^{-2}$ & $8.492 \times 10^{-3}$ & $8.484 \times 10^{-3}$ \\
\hline & $M_{7} / M_{01}$ & $1.147 \times 10^{-2}$ & $1.149 \times 10^{-2}$ & $1.021 \times 10^{-3}$ & $1.023 \times 10^{-2}$ \\
\hline
\end{tabular}

表 1 は，正反射成分だけを有する一壁面からなる矩形室の大 井面の中心に, 完全拡散性正方形光源 $(a=b=1)$ を取り付けた 場合で, 表 2 は桩散反射と正反射成分とを有する壁面の場合で, その正反射成分の反射率は 0.2 としてある.

表 1 , 表 2 上り，近似倠と真值との差はわずかであることがみ

$$
\text { 表 } 2 \text { 各面の光束発散度比 }
$$

$W \times L=5 \times 5$, 光源の面積 $1 \times 1$

光源位置 : 天井面の中心

$\rho_{d 1}=0.9, \quad \rho_{d 2}=0.7, \quad \rho_{d 3}=\rho_{d 4}=\rho_{d 5}+0.2=\rho_{d 6}=\rho_{5}, \quad \rho_{d 7}=0.1$

\begin{tabular}{|c|c|c|c|c|c|}
\hline \multirow{2}{*}{ 室指数 } & \multirow{2}{*}{$\begin{array}{l}\text { 反射率 } \\
M_{1} / M_{01}\end{array}$} & \multicolumn{2}{|c|}{$\rho_{5}=0.7$} & \multicolumn{2}{|c|}{$\rho_{5}=0.7$} \\
\hline & & 值 & 近 似 値 & 値 & 近 似 值 \\
\hline \multirow{7}{*}{0.6} & $M_{1} / M_{01}$ & 1.008 & 1.008 & 1.004 & 1.004 \\
\hline & $M_{2} / M_{01}$ & $6.270 \times 10^{-3}$ & $6.305 \times 10^{-3}$ & $3.535 \times 10^{-3}$ & $3.550 \times 10^{-3}$ \\
\hline & $M_{3} / M_{01}$ & $1.162 \times 10^{-2}$ & $1.161 \times 10^{-2}$ & $6.537 \times 10^{-3}$ & $6.533 \times 10^{-3}$ \\
\hline & $M_{4} / M_{01}$ & $1.164 \times 10^{-2}$ & $1.165 \times 10^{-2}$ & $6.556 \times 10^{-3}$ & $6.558 \times 10^{-3}$ \\
\hline & $M_{5} / M_{01}$ & $8.320 \times 10^{-3}$ & $8.325 \times 10^{-3}$ & $3.936 \times 10^{-3}$ & $3.938 \times 10^{-3}$ \\
\hline & $M_{6} / M_{01}$ & $1.164 \times 10^{-2}$ & $1.165 \times 10^{-2}$ & $6.556 \times 10^{-3}$ & $6.558 \times 10^{-3}$ \\
\hline & $M_{7} / M_{01}$ & $2.305 \times 10^{-3}$ & $2.303 \times 10^{-3}$ & $1.853 \times 10^{-3}$ & $1.853 \times 10^{-3}$ \\
\hline \multirow{7}{*}{1.25} & $M_{1} / M_{01}$ & 1.005 & 1.005 & 1.004 & 1.004 \\
\hline & $M_{2} / M_{01}$ & $4.822 \times 10^{-3}$ & $4.835 \times 10^{-3}$ & 3. $266 \times 10^{-3}$ & $3.269 \times 10^{-3}$ \\
\hline & $M_{3} / M_{01}$ & $1.060 \times 10^{-2}$ & $1.059 \times 10^{-2}$ & $6.539 \times 10^{-3}$ & $6.531 \times 10^{-3}$ \\
\hline & $M_{4} / M_{01}$ & $1.060 \times 10^{-2}$ & $1.060 \times 10^{-2}$ & $6.549 \times 10^{-3}$ & $6.544 \times 10^{-3}$ \\
\hline & $M_{5} / M_{11}$ & $7.574 \times 10^{-3}$ & $7.576 \times 10^{-3}$ & $3.929 \times 10^{-3}$ & $3.928 \times 10^{-3}$ \\
\hline & $M_{6} / M_{01}$ & $1.061 \times 10^{-2}$ & 1. $060 \times 10^{-2}$ & $6.549 \times 10^{-3}$ & $6.544 \times 10^{-3}$ \\
\hline & $M_{7} / M_{01}$ & $3.413 \times 10^{-3}$ & 3. $413 \times 10^{-3}$ & $3.129 \times 10^{-3}$ & $3.130 \times 10^{-3}$ \\
\hline
\end{tabular}

られる。

図 3 は，正反射成分だけを有する一壁面からなる矩形室の各 面の光束発散度比について, 近似值の誤差を下式により求め, 室 指数と䛊差率との関係を示したものである.

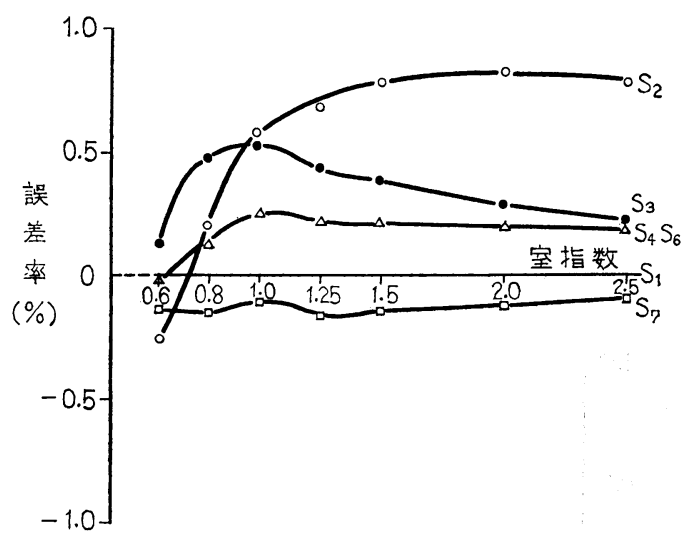

図 3 室指数と䛇差との関保

$W \times L=5 \times 5$

光源の面積： $1 \times 1$, 光源の位值 : 天井面の中心 $\rho_{d 1}=0.9, \quad \rho_{d 2}=0.7, \rho_{d 3}=\rho_{d 4}=\rho_{85}=\rho_{d 6}=0.7$, $\rho_{d 7}=0.3$

表 3 光源の面積変化による各面の光束発散度比 $W \times L=5 \times 5$

$\rho_{d 1}=0.9, \rho_{d 2}=0.7, \quad \rho_{d 3}=\rho_{s 5}=\rho_{d 6}=0.7, \quad \rho_{d 7}=0.3$

\begin{tabular}{|c|c|c|c|c|c|}
\hline \multirow{2}{*}{ 空指数 } & \multirow{2}{*}{$\begin{array}{c}\text { 光源の面積 } \\
M_{1} / M_{10}\end{array}$} & \multicolumn{2}{|c|}{$3 \times 3$} & \multicolumn{2}{|c|}{$5 \times 5$} \\
\hline & & 值 & 近 似 值 & 真 & 近 似值 \\
\hline \multirow{6}{*}{0.6} & $M_{1} / M_{01}$ & 1.088 & 1.089 & 1.089 & 1.266 \\
\hline & $M_{2} / M_{01}$ & $7.028 \times 10^{-2}$ & $7.056 \times 10^{-2}$ & * & * \\
\hline & $M_{3} / M_{01}$ & $1.235 \times 10^{-1}$ & $1.231 \times 10^{-1}$ & $3.681 \times 10^{-1}$ & $3.674 \times 10^{-1}$ \\
\hline & $M_{4} / M_{01}$ & $1.243 \times 10^{-1}$ & $1.242 \times 10^{-1}$ & $3.709 \times 10^{-1}$ & $3.712 \times 10^{-1}$ \\
\hline & $M_{5} / M_{01}$ & $1.243 \times 10^{-1}$ & $1.242 \times 10^{-3}$ & $3.709 \times 10^{-1}$ & $3.712 \times 10^{-1}$ \\
\hline & $M_{d} / M_{02}$ & $6.845 \times 10^{-2}$ & $6.843 \times 10^{-2}$ & $1.890 \times 10^{-1}$ & $1.888 \times 10^{-1}$ \\
\hline \multirow{6}{*}{1.25} & $M_{1} / M_{01}$ & 1.100 & 1.100 & 1.311 & 1.314 \\
\hline & $M_{2} / M_{01}$ & $8.057 \times 10^{-2}$ & $8.027 \times 10^{-2}$ & * & $*$ \\
\hline & $M_{3} / M_{01}$ & $1.401 \times 10^{-1}$ & $1.395 \times 10^{-1}$ & $4.750 \times 10^{-1}$ & $4.746 \times 10^{-1}$ \\
\hline & $M_{4} / M_{01}$ & $1.405 \times 10^{-1}$ & $1.402 \times 10^{-1}$ & $4.730 \times 10^{-1}$ & $4.738 \times 10^{-1}$ \\
\hline & $M_{6} / M_{01}$ & $1.405 \times 10^{-1}$ & $1.402 \times 10^{-1}$ & $4.730 \times 10^{-1}$ & $4.738 \times 10^{-1}$ \\
\hline & $M_{7} / M_{01}$ & $1.018 \times 10^{-1}$ & $1.019 \times 10^{-1}$ & $2.747 \times 10^{-1}$ & $2.752 \times 10^{-1}$ \\
\hline
\end{tabular}

表 4 光源の面積变化に上る各面の光束発散度比

$W \times L=5 \times 5$

$\rho_{d 1}=0.9, \rho_{d 2}=0.7, \rho_{d 3}=\rho_{d 4}=\rho_{s 5}=\rho_{d 6}=0.7, \quad \rho_{d 7}=0.3$

\begin{tabular}{l|l|l|l|l|l|l}
\hline 室指数 & 光源の面積 & \multicolumn{3}{|c|}{$1 \times 3$} & \multicolumn{2}{|c}{$1 \times 5$} \\
\hline$M_{1} / M_{01}$ & 真 & 值 & 近 似值 & 真 & 值 & 近 似 值 \\
\hline & $M_{1} / M_{01}$ & 1.029 & 1.029 & 1.051 & 1.051 \\
\hline$M_{2} / M_{01}$ & $2.297 \times 10^{-2}$ & $2.302 \times 10^{-2}$ & $3.908 \times 10^{-2}$ & $3.921 \times 10^{-2}$ \\
\hline$M_{3} / M_{01}$ & $3.944 \times 10^{-2}$ & $3.931 \times 10^{-2}$ & $6.469 \times 10^{-2}$ & $6.453 \times 10^{-2}$ \\
\hline$M_{4} / M_{01}$ & $4.129 \times 10^{-2}$ & $4.130 \times 10^{-2}$ & $7.304 \times 10^{-2}$ & $7.307 \times 10^{-2}$ \\
\hline$M_{6} / M_{01}$ & $4.129 \times 10^{-2}$ & $4.130 \times 10^{-2}$ & $3.304 \times 10^{-2}$ & $7.307 \times 10^{-2}$ \\
\hline$M_{7} / M_{01}$ & $2.276 \times 10^{-2}$ & $2.278 \times 10^{-2}$ & $3.723 \times 10^{-2}$ & $3.723 \times 10^{-2}$ \\
\hline$M_{1} / M_{01}$ & 1.033 & 1.033 & 1.059 & 1.059 \\
\hline$M_{2} / M_{01}$ & $2.605 \times 10^{-2}$ & $2.598 \times 10^{-2}$ & $4.526 \times 10^{-2}$ & $4.525 \times 10^{-2}$ \\
\hline$M_{3} / M_{01}$ & $4.224 \times 10^{-2}$ & $4.224 \times 10^{-2}$ & $7.073 \times 10^{-2}$ & $7.073 \times 10^{-2}$ \\
\hline$M_{4} / M_{01}$ & $4.628 \times 10^{-2}$ & $4.638 \times 10^{-2}$ & $9.162 \times 10^{-2}$ & $9.179 \times 10^{-2}$ \\
\hline$M_{6} / M_{01}$ & $4.628 \times 10^{-2}$ & $4.638 \times 10^{-2}$ & $9.162 \times 10^{-2}$ & $9.179 \times 10^{-2}$ \\
\hline$M_{7} / M_{01}$ & $3.390 \times 10^{-2}$ & $3.399 \times 10^{-2}$ & $5.445 \times 10^{-2}$ & $5.457 \times 10^{-2}$ \\
\hline
\end{tabular}




$$
\text { 誤差率 }=\frac{M_{i}-M_{i(a)}}{M_{i}} \times 100(\%)
$$

ここで， $M_{i}$ は真值として取り扱った式(8)より求めた光束発散 度比である.

その誤差は, 光源を除いた天井面 $S_{2}$ で最大約 $0.8 \%$ を示して いるが，その他の面では $0.5 \%$ 以下となっている.

表 3，表 4 は正反射成分だけを有する壁面からなる矩形室 で, 光源の面積を変化させたとき, 各面の光束発散度比の近似值 と真值とを比較したもので, 表 3 は正方形光源の大きさを光天井 $(5 \mathrm{~m} \times 5 \mathrm{~m})$ まで変えたとき，表 4 は光源の一辺 $a$ を $1 \mathrm{~m}$ に一 定とし, 辺 $b$ を $1 \mathrm{~m}$ より $5 \mathrm{~m}$ まで变えた場合のものである.

なお，表、において*印は光天井のため, 光源を除いた天井面
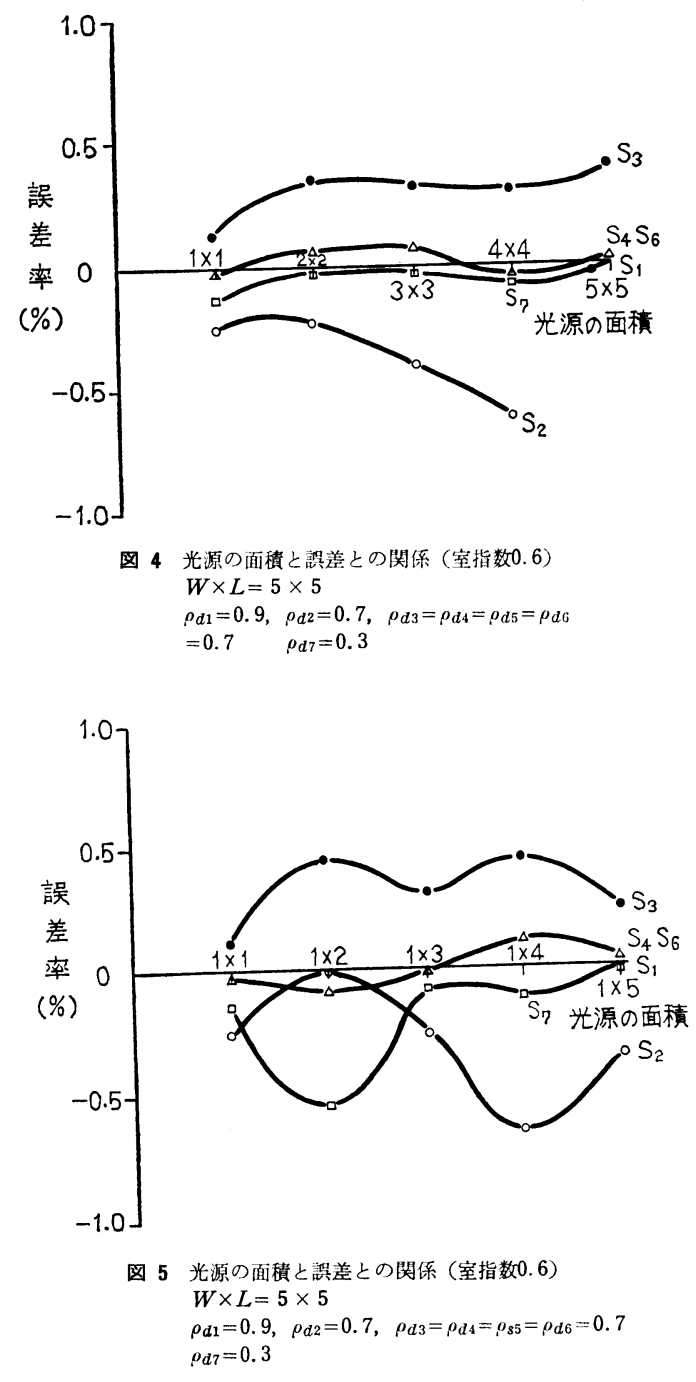

$S_{2}$ が存在しないことを示している.

図 4, 図 5 は, それぞれ表 3 , 表 4 の結果より室指数 0.6 につ いて前述と同様に近似值の誤差を求め示したものである.

光源の面積を变化させた場合も, 前述と同様に近似值による誤 差は各面とも $1 \%$ 以内に拈さまっている.

\section{5. あとがき}

払散反射と正反射成分とを有する壁面からなる室内の相互反射 について近似計算法を試み, 各面の光束発散度比の近似計算結果 と従来より用いられている計算法による結果とを, 光源の大きさ や形状をいろいろ变え比較したところ, 非常に良く一致する結果 が得られた.

このことは，一壁面に拡散反射と正反射成分とを有する室内に おける各面の相互反射後の光束発散度と, 室反射面がすべて完全 拡散性の場合に拈ける各面の光束発散度との差は, その壁面から 1 回反射によって生じた各面の光束発散度の差にほ注等しいと考 えられる.

また従来の計算法では, 室を構成する面素数 $n$ の増加に伴い, $\phi$-関数の計算数も増加し煩雑となるが，本計算法を用いるなら ば $(n-1)$ 個の光束発散度の差 $\Delta M_{1 i}$ を求めることにより, 最大 $1 \%$ 以内の誤差によって計算することが可能である.

なお本報告は，払散反射と正反射成分を有する壁面の全反射率 を一定として取り扱っているが，実際には光の入射角によってそ の全反射率性変化することが考えられるので, 今後は全反射率の 变化を考虑した計算法について検討を重ねるつもりである.

おわりに，本研究の遂行に当たり，ご親切な便宜ならびにご指 導を賜わりましたカリフォルニア大学 Philip F. O'Brien 教授に 心から感謝申し上げるとともに，終始ごべんたつを賜わりました 日本大学生産工学部山内基海教授ならびに, 藤原義輝教授に対し て厚くお礼申し上げます。

\section{参 考 文 献}

(1) O'Brien, P. F., Bobco, R. P.: Illum. Engng. 59 (1964) 337

(2) O'Brien, P. F.: Illum. Engng. 61 (1966) 189

(3) 飯塚, 川島, 石野 : 照学誌 54-3 (昭45) 27

(4) 磯村, 山内：照学誌 64-10 (昭55) 28

(5) 磯村, 山内：照学誌 65-4 (昭56) 16

(6) Dilaura, D. L.: J. Illum. Engng. Soc. 10-2 (1981) 120

(7) Bobco, R. P.: J. Heat Transfer, Trans. ASME 86(1964) 123

（受付1982年 4 月 19日） 